\title{
Research on Resource Integration Mechanism of Science and Technology Innovation Service Platform
}

\author{
Li Yue $^{1 *}$, XU Yongxing ${ }^{1}$, Ma Xiangying ${ }^{1}$, Wu Chuan ${ }^{1}$ \\ ${ }^{1}$ School of Economics and Management, Harbin University of Science and Technology, Harbin, \\ China
}

\begin{abstract}
The resource integration of the scientific and technological innovation service platform is to accurately grasp the changing trend of users' innovation needs through big data, tap potential innovation needs, provide effective innovation services in a timely manner, and improve the utilization efficiency of innovation resources. Through the analysis of resources and the research of reorganization, it is possible to further clarify the integration mechanism of scientific and technological innovation service resources and realize the rapid and healthy development of service resources with technological integration.
\end{abstract}

\section{INTRODUCTION}

Since the beginning of the new century, under the influence of global competition and financial crisis, countries have paid more attention to the quality and efficiency of economic development and have increased investment in scientific research and development and innovation. In order to promote the transformation of economic structure and the development of high-quality economy, China vigorously supports the development of strategic emerging industries, hoping to promote the progress and development of other related industries with its characteristics of high efficiency and strong driving force [1]. In the development of strategic emerging industries, innovation is the core issue. Therefore, the government has issued a series of policies to promote innovation and development. Driven by policy support and economic development trends, innovation and development have ushered in greater opportunities. However, at the same time, innovation and development also face challenges such as low innovation efficiency, high innovation costs, and low effective utilization of resources. Although enterprises are the main force in innovation-driven development, it is difficult for them to obtain all the resources they need with their own capabilities and social network relationships. Intermediaries such as innovation service platforms need to help integrate resources and provide effective innovative services. Moreover, with the development of strategic emerging industries, innovation needs are becoming increasingly personalized, diversified, and professional. Traditional "unified" services cannot meet their needs. It is necessary to integrate and allocate relevant resources according to the specific conditions of the needs. The platform provide highly targeted and highly specialized solutions [2]. Therefore, studying the integration of science and technology service resources, optimizing the allocation of science and technology service resources, and improving the level of science and technology service are of important theoretical value and practical significance for making up for the lack of enterprise innovation resources and promoting enterprise science and technology innovation. This article aims to explore the integration of technology service resources from the perspective of the integration mechanism of technology service resources, hoping to further promote the rapid and healthy development of integration of technology service resources.

\section{RESOURCE ANALYSIS OF SCIENTIFIC AND TECHNOLOGICAL INNOVATION SERVICE PLATFORM}

\section{A. Types and Characteristics of Innovative Servicere Sources}

In the process of matching supply and demand of scientific and technological innovation service platform, it mainly involves service demanders, service providers and service platforms. Service demanders are usually innovative enterprises, In the process of innovation, due to the restriction of resources such as capital, technology, information, talents and professional equipment, they cannot complete the innovation task independently, and need scientific and technological service platforms or scientific and technological intermediaries to provide effective innovation services. Service providers are mainly universities, research institutes, engineering technology centers and some professional technology platforms, which can provide superior scientific and technological resources and specialized services such as

*Corresponding author: lykusha@163.com 
capital, equipment, technology, information and talents, as shown in Table 1 [3]. Efficient and accurate matching between supply and demand of innovative services can greatly improve innovation efficiency, reduce innovation costs and risks, and promote innovation and development of strategic emerging industries.

\begin{tabular}{cl} 
TABLE I. & $\begin{array}{c}\text { TYPES AND FUNCTIONS OF INNOVATIVE SERVICE } \\
\text { RESOURCES }\end{array}$ \\
\hline Resource type & \multicolumn{1}{c}{ Resource function } \\
\hline Talent resources & $\begin{array}{l}\text { Professional talents are the source power to promote } \\
\text { innovation and development and have a direct impact on the } \\
\text { development of innovation activities. The lack of professional } \\
\text { talents is a major obstacle to the development of innovation } \\
\text { activities }\end{array}$ \\
Investment in technology research and development or \\
introduction of advanced technology can accelerate the \\
upgrading and transformation of technology and process and \\
form a competitive advantage \\
All kinds of innovation activities cannot be carried out \\
without financial support, and sufficient financial support can \\
obviously speed up the development process of innovation \\
activities
\end{tabular}

\section{B. The Normative Expression of Innovative Service Resources}

Like innovation demand, innovation service resources should also pay attention to its standardization in expression, Science and technology innovation platform integrates many innovative service resources such as talents, technologies, information and equipment required by users, and must have strict and standardized expression, which is convenient for searching, screening and matching of resources. Specifically, we can learn from the five-tuple model in the computer field, that is, the basic information, category information, status information, function information and quality information of resources, and express the innovative service resources in S Supply accurately and in detail.

1) resource basic information $S_{b a}$ reflects the basic attributes of resources, including name, type (talents, technology, equipment, etc., geographical location and other basic information, which mainly plays the role of resource marking.

2) Resource category information $S_{t y}$, which reflects the types of resources, including R\&D and design, manufacturing, performance and quality inspection and other category information, can preliminarily screen resources.

3) Resource status information Sst, which reflects the current status of resources, including the authenticity, acquisition difficulty and availability of resource information, if available, whether it is idle or occupied at present, available time period, etc.; if it is not available, it is necessary to confirm whether it has been withdrawn or is in the repair stage and can be put into use again.

4) The resource function information $S_{f u}$ reflects the specific functions of resources, which fields and business scopes are mainly used in, what specific problems or types of problems can be solved, and what innovation needs can be met, The resource function information is the key content to be considered when matching supply and demand and is the key factor for further screening resources.

5) The resource quality information $\mathrm{S}_{\mathrm{qu}}$ reflects the quality information of resource service level, service continuity, service reliability, service response time, service cycle time, service cost performance, uniqueness or substitutability, etc., The resource quality information lies in the service priority ranking and matching degree.

\section{RESOURCE REORGANIZATION OF SCIENCE AND TECHNOLOGY INNOVATION SERVICE PLATFORM}

\section{A. Definition of Service Package Attributes}

Modular design of products is a process of clustering to form multiple modules on the basis of basic functional units, The general idea is to analyze the functional, geometric, physical and other correlation relations between products, and obtain the correlation matrix between parts through weight distribution, and then carry out modular partition design by clustering method. Alina Zhang [4] considers customer demand, function and structure correlation, and constructs three objective functions of customer satisfaction, design complexity and assembly complexity, and applies non-dominated sorting genetic algorithm to design the optimal module partition. For innovative services, to reduce the search time and improve the search efficiency, the concepts of service package and service resource module are introduced. Service packages are independent modules that aggregate different service units to meet a certain function, Each functional module can meet a certain innovation demand or several service packages can meet a certain innovation demand, Service units include talents, equipment, technology, scientific and technological information, etc..

\section{B. Service Package Aggregation Based on Service Package Attributes}

The service package is composed of multiple service units Because the service units are not unique, there will be many combinations with similar functions when forming the service package, For example, there will be many professionals in the research and development of graphene mobile phone batteries, and there are many types of design technical solutions. Therefore, some service packages are similar in structure and function, For these service packages, they can be aggregated together in a certain order to form a service resource module, which can meet a certain type of innovation needs of users, as shown in Fig. 1. 


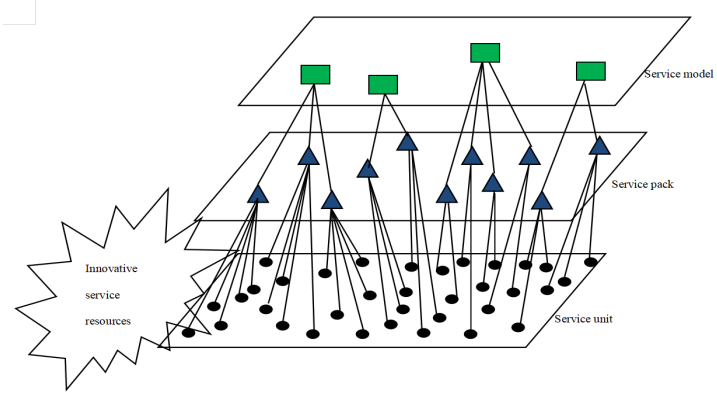

Figure 1. Service Unit and Service Package Aggregation

\section{Modular Construction of Services}

Different service units constitute service packages, and then the service packages with similar functions are gathered together to form a service resource module that can meet a certain type of needs of users, In the process of building service modules, the following points should be paid attention to:

1)Uiversality. The universality of modules is realized through the standardization of their interfaces, and their functions and structures are often serialized according to the serialization principle, to meet the innovation needs of different specifications. The universality of modules is beneficial to realize the universality of modules between horizontal series and vertical series requirements, realize the universality of modules between cross-series innovation requirements, and maximize the utilization rate of modules.

2)Functional independence. Modules have specific functions, which are not the product of arbitrary division of resources, They exist independently rather than depending on other functions. Because the module has specific independent functions, it can be used as a separate design unit for parallel design, which can be independently matched with innovation requirements, and the function and performance of the module can be independently inspected and tested.

3) Unified interface. Interface is the interface of energy and material transfer between demand module and service resource module, and it is also the premise of interchangeability. The module should have an interface (input and output) structure that can transfer functions and form a system. The system is an orderly whole, and the modules combined into the system have relatively independent functions and are connected with each other, The modules are connected in series, parallel, radial or mesh through interfaces to form a system with certain functions.

4) Interchangeability. By standardizing the parameters such as the structure of module interface, it is easy to realize the exchange between modules, so that the module combination can meet the individualized and diversified needs of customers to the greatest extent.

5) Independent structure. The module structure has the characteristics of low external coupling degree and high internal coupling degree and has certain relative independence.
Resource reorganization forms service modules, and the combination of service modules constitutes a service carrier to meet customer needs [5]. Facing the differences and changes of customers' demands, strategic management is to make the internal foundation of an enterprise adapt to the opportunities provided by the external environment, Taking strategic implementation as the intermediate link between the internal and external environment of an enterprise determines that the matching of strategic resources becomes the key issue of strategic implementation. Enterprises dynamically guide and adjust resource input through the combination of modules, If the interdependence between modular service processes is not handled and coordinated accordingly, the system will require the reorganization of resources to improve service quality to meet or exceed customer requirements and expectations. Using flexible customization to form an efficient standardized service production system, such as logistics services, modules can be defined as integrated processes, reduce their complexity and achieve better customer response; especially in the super-competitive environment, the advantages of enterprises focus on designing, organizing, optimizing and managing various internal and inter-organizational business processes, and seek ways to dynamically detect, change and integrate internal and inter-organizational processes [6]. A perfect and effective organization not only provides an appropriate carrier for the operation of resources or elements, but also partially compensates or alleviates the defects in resources and elements, so as to meet the changing business or market opportunities, reconfigure resources and find new market opportunities, which is also the performance of enterprises reorganizing their organizations and changing their departmental responsibilities, and exerting the functions of enterprise resources and resource reuse [7].

\section{Service Priority}

For service resource modules with similar functions and structures, how to sort them when searching for this type of resources has an important impact on the next matching calculation, In this paper, fuzzy comprehensive evaluation method is used to evaluate and sort each service resource module and determine the priority order of service resources.

\section{CONCLUSION AND IMPROVEMENT STRATEGY}

\section{A.Develop Innovative Service Modules}

At present, the innovative service of science and technology service innovation platform mainly provides relevant innovative services for small and medium-sized enterprises, universities and scientific research institutions, including R\&D and design, technical knowledge, mass production, transformation of scientific and technological achievements, etc., In the future, driven by emerging technologies such as cloud platform, big data and industrial internet, enterprises will actively carry out various innovative activities, actively expand their 
business scope externally, develop new products, and promote digitalization and networking internally to improve the efficiency of enterprise operations and reduce costs. The platform should actively grasp the changes of users' needs and actively develop new innovative services, not only related innovative services [8].

For the development of new service modules, the following aspects are mainly considered:

1) The needs of enterprises and markets have changed, and the platform needs to adjust the service scope in time to increase new businesses in enterprises and markets, and these businesses have good development prospects and meet the new innovation needs of users.

2) At present, there are many innovative service platforms at home and abroad, some of which have large scale and wide service scope, and users have good reputation, so they can refer to service modules in other industries at home and abroad.

3) Get the latest trends and trends of industry development through expert consultation, industry forums and seminars, develop new service modules in time, and make a good strategic layout.

4) Keep good communication with users, understand the obstacles of users in carrying out innovative activities and daily operations, and deeply analyze the influence of these obstacles and whether they can be solved by providing innovative services.

\section{B. Expand the Depth of Innovative Services}

When providing innovative services to users, we should not only pay attention to the actual needs of users, but also pay attention to the relevance and extension of needs, why users have such needs and whether they have other related needs, and analyze the characteristics and trends of their needs with the help of big data to provide suitable and targeted service resources. For example, when analyzing the user data, the data analysts of Wal-Mart Supermarket in the United States found that there is a class of users who buy children's diapers as well as beer. In further research, it is found that most of these users are married men, and the purchase time is concentrated on weekends, They will buy some beer to watch the game at home during weekends, and buy diapers for their children by the way. After understanding the relevance of users' demands for these two products, Wal-Mart stores beer and diapers on the adjacent shelves, and the sales have increased significantly. In addition, we should pay attention to the extension of users' needs, dig deep into the root causes of the needs, and provide users with appropriate service resources [9]. (2) At present, there are many innovative service platforms at home and abroad, some of which have large scale and wide service scope, and users have good reputation, so they can refer to service modules in other industries at home and abroad.

\section{Improve the Service Standard System}

In the process of providing innovative resources for users, strict and standardized innovative services can improve user satisfaction and service efficiency and reduce platform operating costs [10]. The platform needs to establish a complete set of innovative service standard system, and it should have strict operation specifications for each stage of innovative service, from demand analysis, acquisition and arrangement to service resource integration and reorganization, and then to supply and demand matching [11]. For each innovative service stage, there should be detailed service standards and service processes, and work instructions should be formulated to ensure the smooth and stable implementation of innovative services [12].

\section{ACKNOWLEDGMENT}

This research was supported by the National Natural Science Foundation of China (71704036);Humanities and Social Science Research Project of the Ministry of Education (19YJA790087); Heilongjiang Province Philosophy and Social Science Planning Project (20GLB119); "Science and Engineering Talents" Program Outstanding Young Talent Project (2019KYYWF-0216)

\section{REFERENCES}

1 DAVIDSON M W, HAIM D A, RADIN J M. Using networks to combine "big data" and traditional surveillance to improve influenza predictions[J].Scientific Reports,2015(5):1-5

2 GINSBERG J, MOHEBBI M H, PATEL R S, et al Detecting influenza epidemics using search engine query data. Detecting influenza epidemics using search engine query data.

3 MALGONDE O, ZHANG H, PADMANABHAN B, LIMAYEM, et al.Taming Complexity In Search Matching: Two-Sided Recommender Systems On Digital Platforms $[\mathrm{J}]$. Mis Quarterly,2020,44(1):49-84.

4 Liang Haiming and Jiang Yanping. Multi-satisfaction stability oriented bilateral matching decision making method considering preference order $[\mathrm{J}]$. Systems Engineering Theory and Practice, 2015,35 (6): 1535-1546.

5 BROWN B, CHUI M, MANYIKA J. Are you ready for the era of 'Big Data' [J]. McKinsey Quarterly, 2011, 4(1):24-35 .

6 DE MAURO A, GRECO M, GRIMALDI M. A formal definition of Big Data based on its essential features.

7 MCAFEE, A. AND BRYNJOLFSSON, E, Big Data: the management revolution[J].Harvard Business Review,2012,90(10):61-67.

8 Wang Xueyuan, Li Tianjiao, Liu Na. Support Strategy of Regional Innovation Platform Based on Enterprise Demand and Co-evolution [J],China Science and Technology Forum, 2015 (02): 102-108

9 GEORGE G, LIN Y. Analytics, innovation, and organizational adaptation [J].Innovation: Management. Policy and Practice, 2017, 19(1):16-22

10 TRABUCCHI D, BUGANZA T, DELLERA C. Exploring the inbound and outbound strategies enabled by user generated Big Data: evidence from leading smartphone applications[J].Creativity and Innovation Management,2018,27(1):42-55

11 [49]TUUNANEN T, CASSAB H. Service process modularization: reuse versus variation in service extensions[J].Journal of Service Research,2011,14(3):340-354. 
12 BOTTCHER M, KLINGNER S. Providing a method for composing modular B2B services [J].Journal of Business \&
Industrial Marketing,2011, 26(5):320-331. 